\title{
AVALIAÇÃO DA APRENDIZAGEM EM FILOSOFIA
}

\section{Carlos Augusto Pereira de Souza*}

Resumo: O presente texto se debruçou sobre as questões relacionadas ao ensino e avaliação da aprendizagem em filosofia após sua presença obrigatória nos currículos de ensino médio do país. Documentos como as Orientações Curriculares Nacionais e o Currículo de Filosofia do Estado de São Paulo indicam uma abordagem de seu ensino pautado por competências e habilidades.

Palavras-chave: Ensino médio. Filosofia. Avaliação. Competências. Habilidades.

Resumen: En este trabajo se ha centrado en cuestiones relacionadas con La enseñanza y evaluación del aprendizaje en la filosofía después de su presencia obligatoria en el plan de estudios de la escuela secundaria en el país. Los documentos como las Directrices Curriculares Nacionales y El Plan de Estudios de filosofía del Estado de Sao Paulo indican un acercamiento a su educación basada en habilidades y capacidades.

Palabras claves: La escuela secundaria. Filosofía. Evaluación. Habilidades. Capacidades.

\section{Introdução}

No ano de 2008 a Filosofia e a Sociologia são incluídas nas três séries do Ensino Médio a partir da Lei $n^{\circ} 11.684 / 08$, que alterou o art. 36 da Lei 9.394/96, tornando-as disciplinas obrigatórias nos currículos escolares do Brasil. Esta mudança foi possível após um longo período que envolveu diferentes práticas e direcionamentos no âmbito educacional, repercutidos em um percurso histórico de extrema importância para a reflexão acerca do ensino de filosofia. A filosofia chega ao Brasil com a Companhia de Jesus no século $\mathrm{XVI}$ e ao lado da Teologia, compôs as chamadas humanidades, fundadas na filosofia de Aristóteles e na teologia de Tomás de Aquino. Foi a partir do século XIX, com as influências do positivismo que o ensino de filosofia passou a ser questionado. "Finalmente, na década de 1940, passou a compor o currículo do curso clássico do colegial" (SÃO

\footnotetext{
" Mestrando em Educação pela Universidade Cidade de São Paulo - UNICID. Endereço eletrônico: carlos-augusto2333@hotmail.com.br
}

PAULO, 2010, p. 114). Nos anos 1960 a filosofia é retirada dos currículos escolares por força de uma reforma de alcance tecnicista da educação básica levada ao fim pelo regime militar implantado no país em 1964 estendendo-se até 1985 , justificava-se à exclusão da Filosofia e de outras disciplinas de humanidades a pouca criticidade e o excesso de tecnicismo na formação dos jovens daquele período.

Conforme São Paulo (2010) nas décadas de 1980 e 1990 a Secretaria de Educação do Estado de São Paulo iniciou uma série de discussóes a fim de promover a elaboração do currículo de filosofia do atual Ensino Médio, contando para isso com a participação das universidades paulistas, publicando versões preliminares de proposta curriculares, retomadas em outro momento.

Em 1996 os conhecimentos filosóficos são reconhecidos a partir da Lei de Diretrizes e Bases da Educação Nacional - Lei $n^{\circ}$ 9.394/96, sendo fundamentais aos exercícios da cidadania. Com os Parâmetros Curricula- 
res Nacionais, foram definidas as competências e habilidades relativas à aprendizagem desses conhecimentos no Ensino Médio.

Para Zuben (2013) só se constrói filosofia a partir da filosofia, entendendo que o ato de filosofar é um contínuo exercício que vai do senso comum ao filosófico e, por sua vez, volta ao senso comum. Esta relação é imprescindível, sem ela o estudo de filosofia é prejudicado.

Este trabalho tem por objetivo compreender as possibilidades dos alunos desenvolverem as habilidades presentes no currículo de filosofia do Estado de São Paulo para o Ensino Médio fazendo uso de instrumentos de avaliação tais como, provas, trabalhos em grupo, pesquisa biográfica e; leitura, análise, compreensão de textos filosóficos. Os resultados colhidos nesta pesquisa poderão contribuir para um direcionamento didáticopedagógico concernente ao processo avaliativo, reafirmando a importância de se refletir sobre as competências e habilidade requeridas ao ensino de filosofia. Para essa empreitada faremos uso da modalidade de pesquisa qualitativa delineada pela análise documental e bibliográfica da qual tem demonstrado eficiente para as demandas nas ciências humanas e sociais. A inquietação junto aos questionamentos sobre como proceder à avaliação numa disciplina reflexiva, da qual não possui um objeto empírico ao qual sustentar-se, em que possa mensurar os resultados ora obtidos. Uma disciplina em que a subjetividade permeia seus fundamentos daí as dificuldades para uma avaliação objetiva, mas que pretendemos demonstrar ser possível através de alguns instrumentos de avaliação já citados, reconhecer a apropriação dos conhecimentos oferecidos aos alunos através de um currículo por competências e habilidade. Junior (2005) entende por habilidades em filosofia como uma organização textual combinando a análise da tradição crítica com os textos fontes e, por conceitos, entende-se o domínio de determinadas concepções filosóficas expostas pelos textos e nas aulas, seja dos comentadores, seja do autor principal.

É sabido que a questão da avaliação em filosofia no ensino médio, ainda é assunto incipiente nas escolas básicas e constitui-se um campo vasto para estudos e pesquisas.

\section{Ensinar filosofia no ensino médio}

Após esse percurso histórico, o ensino de filosofia torna-se tema de discussões, afinal, como pensar em direcionar a aplicabilidade desta disciplina que, em suas raízes mais profundas, utiliza da reflexão e da análise crítica sobre os mais diversos temas, a partir de filósofos de grande expressão conhecidos pela história do pensamento ocidental. Tratando de especificidades que deverão compor os requisitos básicos do currículo de filosofia, conteúdos conceituais e procedimentais. Os primeiros são aqueles relativos ao conhecimento histórico da filosofia, que podem ser definidos pelo ensinar a filosofar, os segundos são os relativos à capacidade de raciocinar a partir desses determinados conteúdos. De acordo com esse entendimento para a avaliação temos, (JUNIOR, 2005, P. 148) "numa primeira perspectiva a avaliação é uma tarefa da docência na qual o professor quer identificar o quanto seus alunos aprenderam sobre determinados conteúdos conceitual ou procedimental por ele ministrado". Desta maneira podemos entender que o ensino da filosofia deve considerar que ela é um produto do pensamento, devendo estar disposta ao diá- 
$\operatorname{logo} e$ possibilitar uma postura crítica frente às discussões surgidas no processo de conhecimento possibilitando introduzir o aluno no "mundo" da filosofia, quer dizer, leva-lo para dentro, inseri-lo numa forma específica de saber, em duplo aspecto: em relação a determinado conteúdo e a certos procedimentos concernentes à aquisição desse conteúdo. Procedimentos metodológicos e conteúdos filosóficos são indissociáveis. A esse respeito cabe reiterar o disposto no texto do PCN sobre o ensino de filosofia ao assinalar que, dada a própria natureza da atividade filosófica, isto é, sua característica reflexiva,

[...] para além do conteúdo concreto a ser ensinado, o que está em questão é, a necessidade de tornar familiar ao estudante um modo de pensar [...]; a conexão interna entre conteúdo e método deve tornar-se evidente: que o estudante tenha se apropriado significativamente de um determinado conteúdo filosófico significa, ao mesmo tempo, que ele se apropriou conscientemente de um método de acesso a esse conteúdo [p. 50].

É importante ressaltar que a característica apresentada deve ser reconhecida, não apenas em um direcionamento, mas principalmente, para os alunos do ensino médio, onde, com as mudanças na legislação vigente, atribui-se às escolas públicas e privadas sua inserção obrigatória nos currículos escolares, após permanecer um longo período distante das instituições de ensino devido seu caráter reflexivo e crítico a respeito das marcas ideológicas, políticas e sociais em que o país se encontrava naquele momento.

Sua inserção representa uma possibilidade quanto à contribuição de seu ensino para a qualidade na educação de muitos jovens, que tendo seu primeiro contato com a filosofia no ensino médio, ingressarão em cursos superiores com conhecimentos significativos para um aprofundamento reflexivo $e$ sistemático. Ou seja, uma das perguntas contidas nas discussões acerca do ensino da filosofia também permeia quanto à possibilidade de apreensão de conteúdos que estejam associados ao desenvolvimento de competências e habilidades nos currículos escolares.

\section{Do ensino de filosofia por competências $e$ habilidades}

O ensino por competências é muito discutido na atualidade e no embasamento que vem ocorrendo na formulação de currículos escolares, nos remete a pensar que seu surgimento se deve à crise dos referentes tradicionais, que pode ser analisada a partir de fatores, como destaca Zabala (2010) para uma ascensão do ensino baseado no desenvolvimento de competências motivado pela crise de fatores exigindo mudanças na universidade, instituição pouco dada à mudança, mas que a partir de convergência europeia esta replanejando suas estruturas quanto aos conteúdos; é notória a pressão social sobre a necessária funcionalidade das aprendizagens que força a introdução de competências, o questionamento sobre a desconexão entre teoria e prática; é de suma importância referir à função social do ensino. Assim sendo competência pode ter a seguinte definição:

Competência é a capacidade que as pessoas desenvolvem de articular, relacionar os diferentes saberes, conhecimentos, atitudes e valores, construídos por intermédio de sua vivencia e por meio dos conhecimentos construídos na escola (CRUZ, 2010, P. 29).

Tal articulação relaciona na construção a partir das necessidades da vida diária, das emoções e dos desafios que temos de enfrentar com as quais devemos dialogar. Desta 
feita competência implica em operacionalizar conhecimentos, atitudes e valores. Competência é uma ação cognitiva, afetiva e social que é demonstrável nas práticas e ações que se exerce sobre o conhecimento, o outro e a própria realidade.

As competências contribuem para o processo de aprendizagem na medida em que percebemos sua relação com as formações do sujeito frente ao conhecimento. Porém, as competências não se referenciam sozinhas no ensino, necessitando serem acompanhadas por habilidades específicas, que farão com que o aluno saiba o que é pressuposto em determinada competência.

As habilidades, ou o saber-fazer são os componentes da competência explicitáveis na ação. Figura polêmica das discussões sobre a teoria das competências, ela é um híbrido de recurso e resultado. Em outras palavras, quando as capacidades são colocadas a serviço da ação, competências são desenvolvidas e se tornam aprendizados interiorizados pelos sujeitos (RAMOS, 2001 apud CRUZ, 2010, p. 49-50).

As habilidades são a dimensão mais explicitável da competência, elas costumam, tornar-se indicadores de desempenho visando à avaliação do desenvolvimento das competências previstas. Lorieri (2002) entende ser imprescindível para o ensino de filosofia a presença das habilidades básicas do pensamento conhecidas habilidades de investigação, observação e formulação de questões; habilidades de raciocínio, responsáveis por produzir juízos, estabelecer relações entre ideias; e as habilidades de formação de conceitos com propriedades para explicar o significado de qualquer palavra, analisar elementos que compõe um conceito qualquer.

\section{Competências e habilidades no currículo de filosofia de São Paulo}

Conforme os pressupostos descritos sobre o ensino da filosofia, as competências e habilidades passaram a ocupar um espaço significativo na estrutura curricular do estado de São Paulo a partir de 2008, quando a rede pública sofreu uma reformulação e pode oferecer um currículo básico para todas as disciplinas constantes no ensino fundamental e médio. Desde sua implantação, o currículo de São Paulo ocupou-se em expressar eixos norteadores em sua estrutura pedagógica, como forma de garantir que os conteúdos pudessem ser desenvolvidos através de competências, entendendo-as como elementos essenciais para um ensino direcionado à melhoria da aprendizagem, e contemplando-as a partir de três princípios: "Princípio das competências como referência; princípio da prioridade para a competência da leitura e da escrita; princípio da articulação das competências para aprender" (SÃO PAULO, 2010, p. 12-18).

No que diz respeito às competências para o ensino da filosofia, o currículo de São Paulo estruturou-se a partir das Orientações Curriculares para o Ensino Médio (BRASIL, 2006, p. 33-34, vol.3), que as descreve sob a perspectiva de três grupos:

1. Representação e comunicação: ler textos filosóficos de modo significativo; ler de modo filosófico textos de diferentes estruturas e registros; elaborar por escrito o que foi apropriado de modo reflexivo; debater, tomando uma posição, defendendo-a argumentativamente e mudando de posição em face de argumentos mais consistentes.

2. Investigação e compreensão: articular conhecimentos filosóficos e dife- 
rentes conteúdos e modos discursivos nas ciências naturais e humanas, nas artes e em outras produções culturais.

3. Contextualização sociocultural: Contextualizar conhecimentos filosóficos, tanto no plano de sua origem específica quanto em outros planos: o pessoal-biográfico; o entorno sóciopolítico, histórico e cultural; o horizonte da sociedade científicotecnológica.

Assim sendo, as competências para o ensino de filosofia nos levam a refletir sobre seus propósitos mais precisos em um espaço que esteja aberto ao diálogo permanente $e$ disposto a conscientizar o indivíduo, podendo ser abordada sob a perspectiva sociocultural e reflexiva.

Na sequência trazemos alguns conteúdos básicos contidos no Currículo de Filosofia de São Paulo (SÃO PAULO, 2010, P. 120-129) que devem ser apreendidos bimestralmente, visando sempre o desenvolvimento de habilidades específicas: Conteúdos e Habilidades da $1^{\mathrm{a}}$ série do Ensino Médio:

Conteúdos:

- Por que estudar filosofia?

- As áreas da filosofia

Habilidades:

- Identificar informações em textos filosóficos

- Identificar características de argumentação em diferentes gêneros textuais

- Relacionar questões atuais a questões da História da Filosofia

Conteúdos e Habilidades da $2^{a}$ série do Ensino Médio.

Conteúdos:

- O eu racional

- Autonomia e liberdade
Habilidades:

- Questionar a realidade social e planejar ações de intervenção solidária

- Relacionar liberdade à solidariedade

- Relacionar ética e moral

Conteúdos e Habilidades da $3^{a}$ série do Ensino Médio.

Conteúdos:

Características do discurso filosófico

- Comparação com o discurso religioso

O homem como ser político

A desigualdade entre os homens como desafio da política

Habilidades:

- Identificar marcas dos discursos filosóficos, mitológico e religioso.

- Elaborar hipóteses e questões a partir de leituras e debates realizados

- Questionar o papel social do Estado e das leis.

\section{Avaliação em filosofia pautada em compe- tências e habilidades}

As competências e habilidades próprias do currículo ao abrangermos a avaliação em filosofia, afinal, há muito por esclarecer sobre o tema, visto que o termo "avaliação" tornase amplo na medida em que abrange concepções, instrumentos e formas variadas no que diz respeito ao acompanhamento da aprendizagem e que deve ser feito constantemente pelo professor no decorrer das aulas, classificando e justificando critérios de verificação das competências e habilidades desenvolvidas pelos alunos. Nessa perspectiva faz necessário que o professor reorganize seus planejamentos, para que possa fornecer aos educandos uma educação de qualidade contemplando os avanços individuais bem como os coletivos. Ou seja, "[...] seria interessante 
que o julgamento final sobre o educando fosse emitido baseado em múltiplas situações, diferentes avaliadores e múltiplos instrumentos de avaliação" (DEPRESBITERIS e TAVARES, 2009, p. 57).

O processo de ensino e aprendizagem no ambiente escolar implica na verificação de resultados alcançados pelos educandos, portanto, a escola e os professores são a base no desenvolvimento integral na medida em que ampliam oportunidades de aprendizagem que priorizem a educação. Sabe-se que uma avaliação constante quer seja no momento de ensinar, quer seja no momento de aprender, deve acompanhar o processo de ensino $e$ aprendizagem, onde o professor é agente do conhecimento e o educando o descobridor deste. Nessa perspectiva a aprendizagem escolar é resultante de uma proposta pedagógica onde o professor propõe uma aprendizagem significativa para o educando, para que o mesmo possa se apropriar destes conhecimentos, sendo que a avaliação é que subsidia decisões a respeito da aprendizagem dos educandos.

Ao analisar a avaliação como instrumento de dominação e classificação, nota-se o uso da atividade avaliativa em uma perspectiva marcada pela presença da exigência, onde predomina a seleção e métodos tradicionais na forma de avaliar. Conforme Depresbiteris e Tavares (2009, p. 39) "a questão crucial é descobrir o que é preciso fazer para criar e desenvolver avaliações realmente utilizadas para reduzir incertezas, melhorar a afetividade [...]".

É importante ressaltar que o professor deve recorrer aos instrumentos de avaliação, mapeando o que deseja saber sobre a aprendizagem dos educandos, pois isto o ajudará na coleta de dados, na correção do próprio instrumento avaliativo proposto por ele, bem como na leitura dos resultados, levando em consideração a importância de manter o educando informado quanto ao seu desempenho, seus esforços e avanços no decorrer do processo de ensino.

Ainda incorrendo pelo mesmo raciocínio, temos que, a avaliação deve ser vista como fundamental no processo educativo, na medida em que pode e deve sinalizar direções a serem percebidas pelo professor como forma de possíveis adequações na abordagem dos conteúdos, bem como nas competências $e$ habilidades requeridas para a disciplina de filosofia.

De acordo com Behrens:

Avaliação no ensino com pesquisa apresenta-se continua processual e participativa. $\mathrm{O}$ acompanhamento dos alunos em projetos $e$ pesquisas tem como norteador a proposição de critérios discutidos e construídos com os alunos antes de começar o processo... O aluno é avaliado pelo desempenho geral $e$ globalizado, com acompanhamento do seu ritmo participativo e produtivo, todo dia $e$ não por momentos de grande esforço de memorização e cópia no final do bimestre. (BEHRENS, 2005, p. 102)

Estas colocações apontadas revelam que a avaliação é voltada para o aprendizado, participativa e para o desenvolvimento do aluno no decorrer da caminhada educativa.

Silva (1996) aponta para os reflexos da avaliação e dos seus resultados sobre as pessoas e sobre as próprias comunidades educativas, exigiram que os estudos sobre a avaliação tentassem minimizar os riscos de subjetividade, falta de rigor e de controle interno dos mecanismos utilizados. Assim surgiram crescentes exigências científicas quanto à ra- 
cionalidade, sistematicidade, controle de variáveis, confiabilidade dos instrumentos, etc., num esforço de rigor e de objetividade. Porém, a "força" do rigor mede-se pela rigidez e artificialidade das situações criadas pela aplicação dos processos científicos de avaliação. Assim, as prova objetivas, testes estandardizados, observação através de categorias operativadas, embora permitam uma maior exatidão dos dados recolhidos, rompem com a naturalidade da conduta habitual dos alunos e podem comprometer, não só a relação pedagógica, como a possibilidade de desenvolvimento dos mais elevados níveis do desenvolvimento pessoal cognitivo e afetivo. Por outro lado, a procura de modelos quantitativos rigorosos nos processos de avaliação baseia-se numa concepção tradicional de escola para a qual o que mais importa são os resultados alcançados pelos alunos e não o processo de desenvolvimento dos sujeito. Diferente do que pensa os defensores dos modos tradicionais de avaliação entende que "o que é preciso clarear é que as formas de avaliação são mediadoras de conhecimentos, uma vez que interiorizam o que é desempenho ideal, tanto nos professores quanto nos alunos" (RAPHAEL, 1995, P. 41).

Qualquer professor conhece por experiência que os conhecimentos sobre os quais repousa a avaliação dos seus alunos são muito mais ricos, variados e profundos do que os indicadores colhidos em testes, exercícios, ou outros meios tantas vezes superficiais, a que o professor tem de sujeitar em nome do rigor científico da medição imposta pelo sistema de avaliação em vigor. A partir do momento em que o ato de avaliação é determinado por fatores que são estranhos ao processo de aprendizagem, de modo que, tal fato pode refletir-se diretamente na seleção de conteúdos, nas estratégias adotadas pelo professor, nos instrumentos que ele mesmo concebe para aperfeiçoar os mecanismos da comunicação e da aprendizagem, estão criadas as condições para as perversidades e os vícios de um ensino que não serve a liberdade, a descoberta de si e do mundo, a autêntica relação pedagógica enquanto relação pessoal, a procura da verdade nos vários campos do saber.

Esta visão de ensino pode ser acusada de certo idealismo. Poder-se-á afirmar que o ato educativo é também um ato político $e$ que as preocupações pela educação constituem hoje um importante campo de intervenção ideológica através das políticas e éticas educativas. Sem uma minuciosa investigação e sem a procura de procedimentos inovadores que surja de um questionamento filosófico da pedagogia, esta concebida como verdadeira "arte de ensinar", o ensino sem a criatividade, será mera transmissão de conhecimentos e, em particular o ensino de filosofia, poderá reduzir-se, quiçá, ao senso comum de uma moralidade cívica.

Conquanto, a verdadeira utilidade da avaliação não depende da sua função política, embora seja inegável que a tenha, nem se esgota no utilitarismo do plano técnico das didáticas formais que analisam critérios e instrumentos. A verdadeira função da avaliação reside no seu papel formativo, na sua função autorreguladora enquanto ponto de vista crítico do trabalho desenvolvido.

\section{Considerações finais}

O ensino de filosofia assim como o objetivo da própria disciplina no currículo escolar, cumpre a função de dialogar com ideias $e$ 
possibilidades, oferecer caminhos para conduzir a aula a um espaço aberto aos questionamentos, às dúvidas, incertezas e descobertas, na medida em que os alunos possam também perceber as potencialidades de uma educação capaz de transformar e oportunizar um novo olhar da realidade.

Um currículo estruturado através de competências e habilidades poderá oferecer uma melhor adequação dos conteúdos propostos para cada série do ensino médio, direcionando a ação docente e possíveis atividades que venham a contemplar as exigências de um ensino da filosofia voltado para o diálogo e a reflexão crítica. A avaliação em filosofia deve ocorrer de forma integradora, ou seja, a prova objetiva, por exemplo, deve ser entendida como um dos instrumentos avaliativos, que pode contribuir para mensurar quantitativamente se as habilidades foram desenvolvidas e puderam ser alcançadas. Porém, de nada vale resultados quantitativos se não houver uma reflexão qualitativa desses resultados, a ponto de despertar no professor a necessidade de buscar novas alternativas no ensino e oferecer também mudanças nas condições de aprendizagem dos alunos.

Os encaminhamentos devem ocorrer na medida em que o professor identifica, a partir de um acompanhamento mais sistemático, as condições para criar estratégias diferenciais de acordo com a realidade dos alunos e suas respectivas séries. As habilidades poderão ser verificadas nas provas objetivas desde que os alunos também estejam conscientes do que elas representam para sua aprendizagem $e$ quais caminhos devem percorrer para que o processo educativo torne-se algo prazeroso $e$ não meramente obrigatório.

Para concluir: Espera-se que a avaliação em filosofia seja pensada integralmente no contexto dos processos de aprendizagem da própria filosofia e não concebida como algo estranho, que permitam medir de forma objetiva o sucesso ou insucesso da aprendizagem. Com efeito, importa mostrar como poderiam ser inovadoras as investigações sobre a avaliação em filosofia que revalorizasse a dimensão qualitativa revelando o que à filosofia importa. O fascínio do quantitativo conduz a uma depreciação dos processos qualitativos $e$ gera como que um sentimento de inferioridade das disciplinas de humanidades, onde a quantificação se afigura mais problemática $e$ de difícil aplicação, perante as disciplinas científicas, (matemática e física, por exemplo), onde os métodos quantitativos imperam.

\section{Referências}

BEHRENS, Marilda Aparecida. O Paradigma emergente e a prática pedagógica. $4^{\mathrm{a}}$ Edição, $\mathrm{Cu}$ ritiba, PR: Editora Universitária Champagnat. 2005.

BRASIL, Lei $\mathrm{N}^{\circ}$ 11.684, de 02 de Junho de 2008. Altera o art. 36 da Lei o 9.394, de 20 de dezembro de 1996, que estabelece as diretrizes e bases da educação nacional, para incluir a Filosofia e a Sociologia como disciplinas obrigatórias nos currículos do ensino médio. Disponível em: http://www.planalto.gov.br/ccivil_03/_Ato20072010/2008/Lei/L11684.htm. Acesso em: 21 de maio de 2016. 
BRASIL, Lei № 9.394, de 20 de Dezembro de 1996. Estabelece as diretrizes e bases da educação nacional. Disponível em: http://www.planalto.gov.br/ccivil 03/leis/L9394.htm. Acesso em: 21 de maio de 2016.

BRASIL, Parâmetros Curriculares Nacionais. Ensino Médio. V. IV Ciências Humanas e suas Tecnologias, Brasília, DF: Ministério da Educação/ Secretaria de Educação Média e Tecnológica, 1999.

BRASIL. Orientações Curriculares para o Ensino Médio: Ciências humanas e suas tecnologias. Brasília: Ministério da Educação, Secretaria de Educação Básica, 2006.

CRUZ, Carlos Henrique Carrilho. Competências e habilidades: da proposta à prática. São Paulo: Loyola, 2010.

DEPRESBITERIS, Léa; TAVARES, Marialva Rossi. Diversificar é preciso: instrumentos e técnicas de avaliação da aprendizagem. São Paulo: Editora SENAC SP, 2009.

JUNIOR, José Benedito de Almeida. A Avaliação em filosofia. Revista Princípios, Natal, vol. 12, n. 17-18, jan./dez. 2005, p. 145-156.

LORIERI, Marcos Antônio. Filosofia: fundamentos e métodos. São Paulo: Cortez, 2002.

RAPHAEL, H. S., Avaliação: questão técnica ou política. Revista Estudos em Avaliação Educacional, n. 12, p. 33-43, 1995.

SÃO PAULO. Currículo do Estado de São Paulo: Ciências humanas e suas tecnologias. São Paulo: Secretaria de Estado da Educação, 2010.

SILVA, Isabel Medina. A avaliação no ensino de filosofia. Revista Philosophica 7, Lisboa, Edições Colibri, 1996, p. 151-156.

ZABALA, Antônio. Como aprender e ensinar competências. Porto Alegre, RS: Artmed, 2010.

ZUBEN, Marcos de Camargo Von; ARAÚJO, Joelson Silva de; COSTA, Izanete de Medeiros. Avaliação dos principais livros didáticos de filosofia para o ensino médio existentes no mercado editorial brasileiro. Revista Sul-Americana de Filosofia e Educação - RESAFE, n. 20: Maioout./2013 p.157-178.

Recebido em: 03/09/2016

Aprovado em: 20/10/2016 